\title{
Effect of xylitol-, sucrose-, and water-rinses on the composition of human palatine gland secretions
}

\author{
KAUKO K. MÄKINEN*, KAUKO K. VIRTANEN**, EVA SÖDERLING*** AND JARMO \\ KOTIRANTA** \\ ${ }^{*}$ School of Dentistry, The University of Michigan, Ann Arbor, Michigan, USA, ${ }^{* *}$ Department of Prosthetics, Institute \\ of Dentistry, University of Oulu, Oulu, and ***Department of Biochemistry, Institute of Dentistry, University of \\ Turku, Turku, Finland
}

\begin{abstract}
Mäkinen, KK, Virtanen KK, Söderling E, Kotiranta J: Effect of xylitol-, sucrose-, and waterrinses on the composition on human palatine gland secretions. Scand J Dent Res 1985; 93: 253-61.

Abstract - The chemical composition of stimulated human palatine secretions (HPS) was studied after rinsing with aqueous solutions of sucrose or xylitol, or with water only. Stimulation with water was associated with increased concentration levels of protein. The levels of sialic acids (per $\mathrm{mg}$ protein) and the specific arylamidase activities were simultaneously increased, within the physiologic range. In contrast to a previous report, these results indicate that HPS does contain arylaminopeptidases the activity of which is strongly increased by $\mathrm{Cl}^{-}$. The $\mathrm{Cl}^{-}$-dependent activity was revealed when using $\mathcal{N}$-L-arginyl-2-naphthylamide as substrate. The filter paper method used is recommended for collecting HPS for chemical analyses. In spite of the use of a relatively effective and versatile stimulation procedure, only one third of the subjects produced detectable HPS. Very poor secretion of HPS should perhaps be considered in subjects wearing total dentures.
\end{abstract}

Key words: aminopeptidases; palatine secretions; saliva; sucrose; sweeteners; xylitol.

K. K. Mäkinen, School of Dentistry, The University of Michigan, Ann Arbor, Michigan 48109, USA.

Accepted for publication 26 August 1984 .

Our previous report on human palatine gland secretions (HPS) provided information on the chemical composition of these secretions, obtained by mechanical stimulation of the palate (1). There has been no published study on the effects of chemical stimuli on HPS, although such experiments have been carried out with mixed saliva and saliva collected from the major salivary glands. One of the purposes of this study was to investigate whether xylitol and sucrose which usually exert quite different effects on the biology of the oral cavity (2-4), would differ in their effects on the composition of 
HPS. Another rationale behind this study was the discovery of arylamidases in HPS (1). Because the enzyme spectrum of HPS seemed to be very narrow, it was considered necessary to investigate the activity levels of these arylamidases, which appeared to be dominant HPS enzymes. HPS was collected in this study using a filter paper method, following a short chemical stimulus with aqueous solutions of sucrose or xylitol. The new collection procedure may be considered simpler than our previous technique (1) involving the use of glass capillaries and suction.

\section{Material and methods}

Chemical methods - These were described in our previous report (1). Consequently, the following components and enzymes of HPS were determined: total protein (after $\mathrm{NaOH}$ treatment), total sialic acids (after $\mathrm{H}_{2} \mathrm{SO}_{4}$ hydrolysis), total carbohydrates (after $\mathrm{NaOH}$ treatment), and arylamidase activity tested with $\mathcal{N}$-L-leucyl-2naphthylamide, $\mathcal{N}$-L-alanyl-2-naphthylamide and $\mathcal{N}$-L-arginyl-2-naphthylamide as substrates (Leu2-NA, Ala-2-NA and Arg-2-NA; Koch-Light Laboratories Ltd, Colnbrook, England). The protein determinations needed in the calculation of the specific activity of enzymes were carried out on the aqueous extracts of paper discs. In order to reveal the involvement of specific $\mathrm{Cl}^{-}$-dependent arginine aminopeptidases (EC 3.4.11.6) $(5,6)$, the hydrolysis of Arg-2-NA was tested in the presence of $0.2 \mathrm{M} \mathrm{NaCl}$ and without added salt. Our previous studies on the $\mathrm{NaCl}$ effects of aminopeptidases have shown that $0.2 \mathrm{M} \mathrm{NaCl}$ can be used to differentiate between $\mathrm{Cl}^{-}$-dependent and $\mathrm{Cl}^{-}$inhibited enzymes (7-11).

Collection of HPS - Human palatine gland secretions were collected from 19 20-35-yr-old women (mean age 30.7 yr) during February-March 1983. This group included the same subjects who participated in our previous study (1). The initial material consisted of 60 subjects of whom 19 secreted HPS at a rate that was necessary for the present study (see below). All collections were performed between 9 and 11 a.m., at least $2 \mathrm{~h}$ after breakfast and regular oral hygiene procedures. The collections were carried out after three different types of chemical stimuli: rinsing for $2 \mathrm{~min}$ with $5 \mathrm{ml}$ of a $10 \%(\mathrm{w} / \mathrm{v})$ aqueous solution of sucrose (BDH Chemicals Ltd, Poole, England) or xylitol (Xyrofin Ltd, Baar, Switzerland), or distilled water only (all at $25^{\circ} \mathrm{C}$ ), with simultaneous chewing of a $0.9 \mathrm{~g}$ piece of paraffin (m.p. $50^{\circ} \mathrm{G}$ ). The mechanical stimulus caused by paraffin chewing was thus identical in all experiments. Following the 2-min rinsing-chewing stimulus, cotton rolls were placed in the buccal sulcus to prevent parotid products from mixing with HPS. An aspirator was placed in the mouth and the tongue was held down with a mouth mirror or a spatula. The area producing HPS was thus isolated from other oral tissues and secretions. The palate was then thoroughly rinsed with a water spray and dried gently with sterile dressing. These sprayingdrying procedures were identical in all cases and they lasted for $30 \mathrm{~s}$. Three round filter paper discs (diameter $5 \mathrm{~mm}$ and dry weight $4.4 \mathrm{mg}$; made from Whatman No. 3 paper) were then placed on each side of the soft and hard palate for the collection of HPS (6 discs per subjects; Fig. 1). In each experiment the paper discs were inserted as accurately as possible on the same sites. This was controlled by visually evaluating the distance of the discs from the midline of the palate. During HPS collection, the posterior soft palate area beyond the paper discs was gently irritated with a blunt, sterile instrument. This mechanical stimulus was similar in all experiments. After due practice, the time between finishing the 2-min rinsing-chewing period and placing the first paper disc (start of HPS collection) was set to $1 \mathrm{~min}$ in all subsequent experiments. The collection time was 5 min. After collection of HPS, the six paper discs were inserted into plastic capsules containing 0.5 $\mathrm{ml}$ distilled water. This water was considered to prevent the HPS constituents from being absorbed too much into the paper discs. The capsules were then tightly sealed and stored at $-20^{\circ} \mathrm{C}$ until all subjects were treated. The HPS samples were analyzed simultaneously about $4 \mathrm{wk}$ following the treatments.

All 19 subjects were treated with the three chemical stimulants. Depending on the success in the treatment and collection procedures, samples from 16-19 subjects were analyzed chemically. The space between the treatments given to each subject was 3-7 days; thus there should have been no carry-over effects from the treatments.

Treatment of filter paper discs - After thawing, the contents of the sample tubes were shaken for $30 \mathrm{~s}$ with a Vortex mixer, followed by centrifugation for $10 \mathrm{~min}$ at $12100 \mathrm{~g}$. The supernatant fluids extracted from the paper discs in $0.5 \mathrm{ml}$ water were analyzed for arylamidase activity and protein. These enzyme and protein data were used for calculation of specific arylamidase activities. The paper discs that were spun down were treated with 


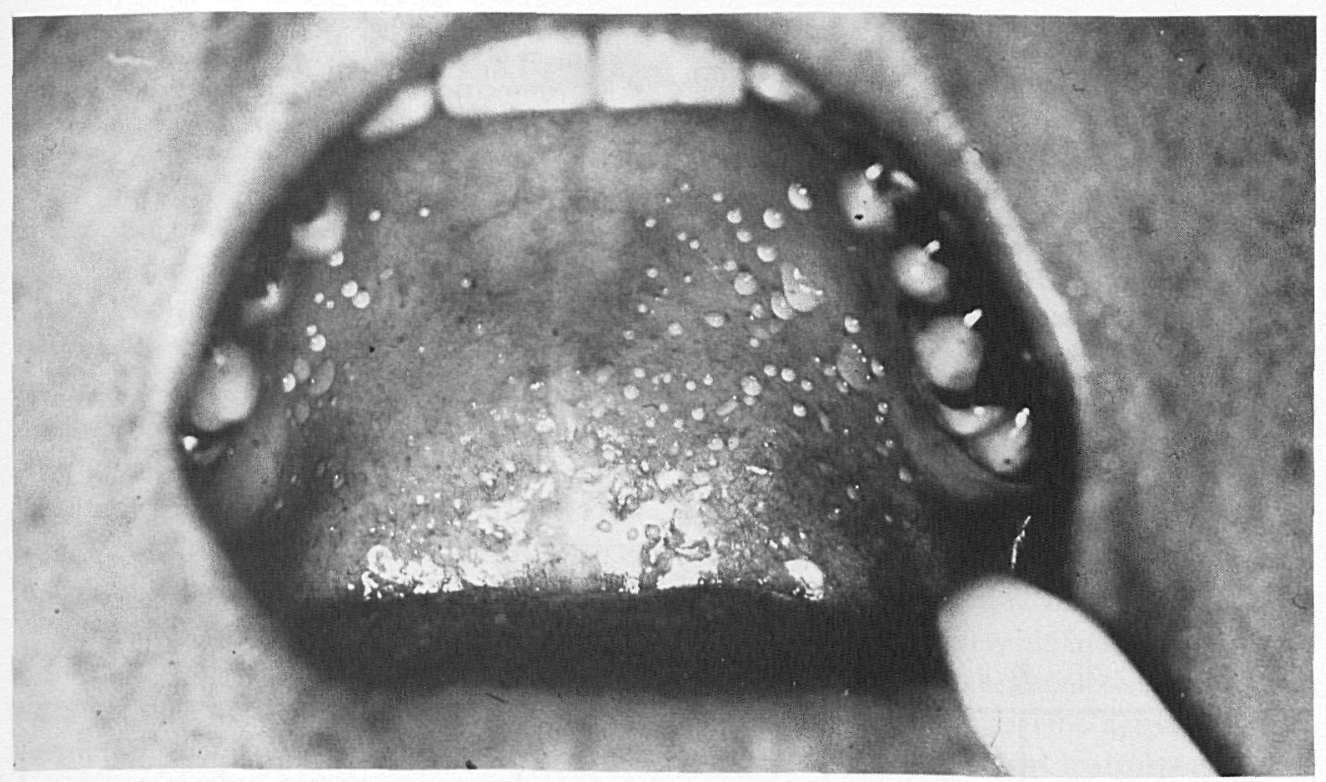

A

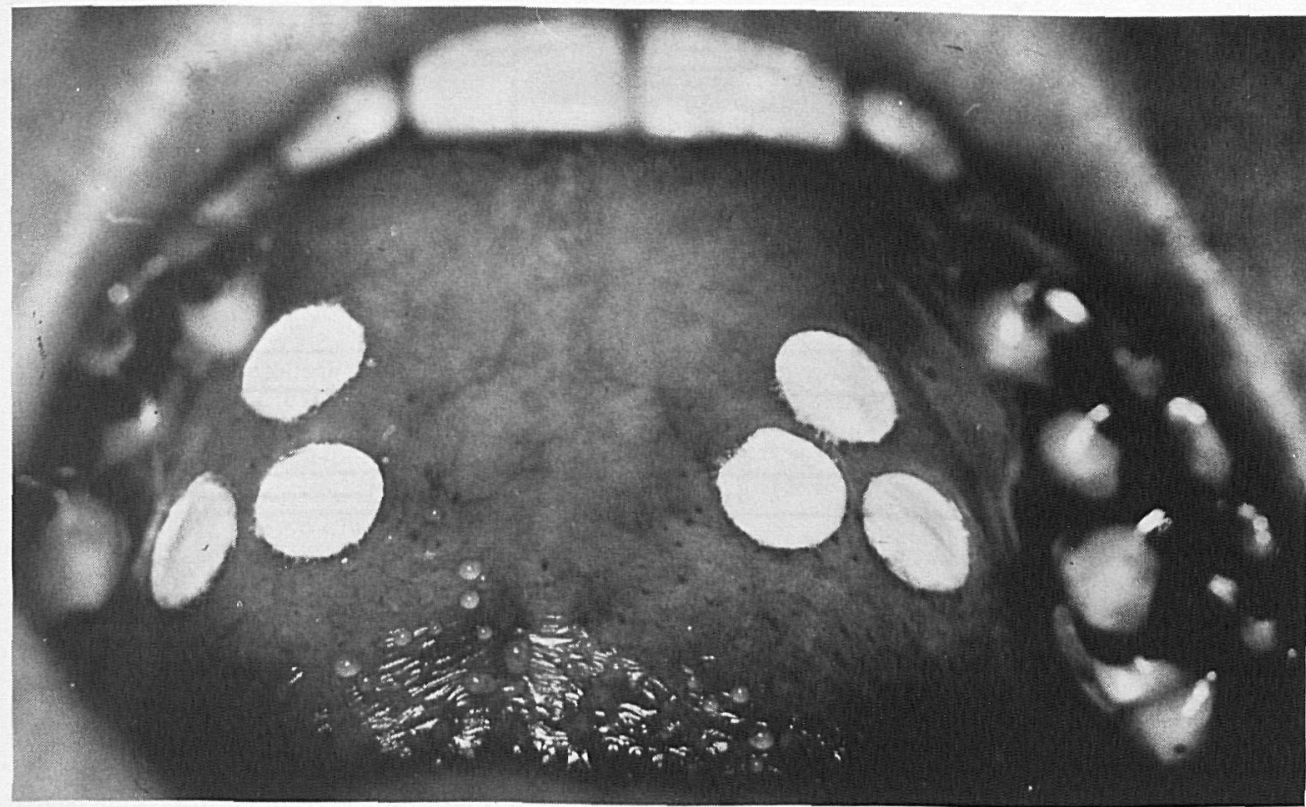

B

Fig. 1. Collection of HPS by filter paper method. A, appearance of HPS following 2-min gentle, mechanical stimulation (in the study proper, similar appearance of HPS was found following combination of stimulations). B, filter paper discs placed for collection. Note that more HPS was secreted from the left palate than from the right palate. 
$0.3 \mathrm{M} \mathrm{NaOH}$ at $100^{\circ} \mathrm{C}$ for $20 \mathrm{~min}$, following by centrifugation at $12100 \mathrm{~g}$ for $10 \mathrm{~min}$. The supernatant fluids were analyzed for protein, total sialic acids and total carbohydrates (1). The above water extracts of unused filter paper discs gave small extinctions that were always subtracted from those obtained in the analyses of the used paper discs. Consequently, the small amounts of glucose polymers and protein that might have been present in the paper discs did not affect the results.

Calculation of results - Because there is no reliable method for the determination of the exact flow rate, volume or weight of total HPS, the chemical data were expressed per $\mathrm{mg}$ protein that could be reliably measured. Our studies indicated that even weight determinations were subject to considerable error due to evaporation losses that occurred during the 5-min collection period. The statistical treatment of the results was performed using both the parametric t-test for paired comparisons and the nonparametric Wilcoxon matched-pairs signed-ranks test.

\section{Results}

The secretion rates of HPS varied greatly from subject to subject. Five of the 19 women included in the final study were very good secretors, five were regarded as good and six as moderate secretors. Three subjects produced HPS at a low rate. Forty-one of the original 60 subjects produced extremely little

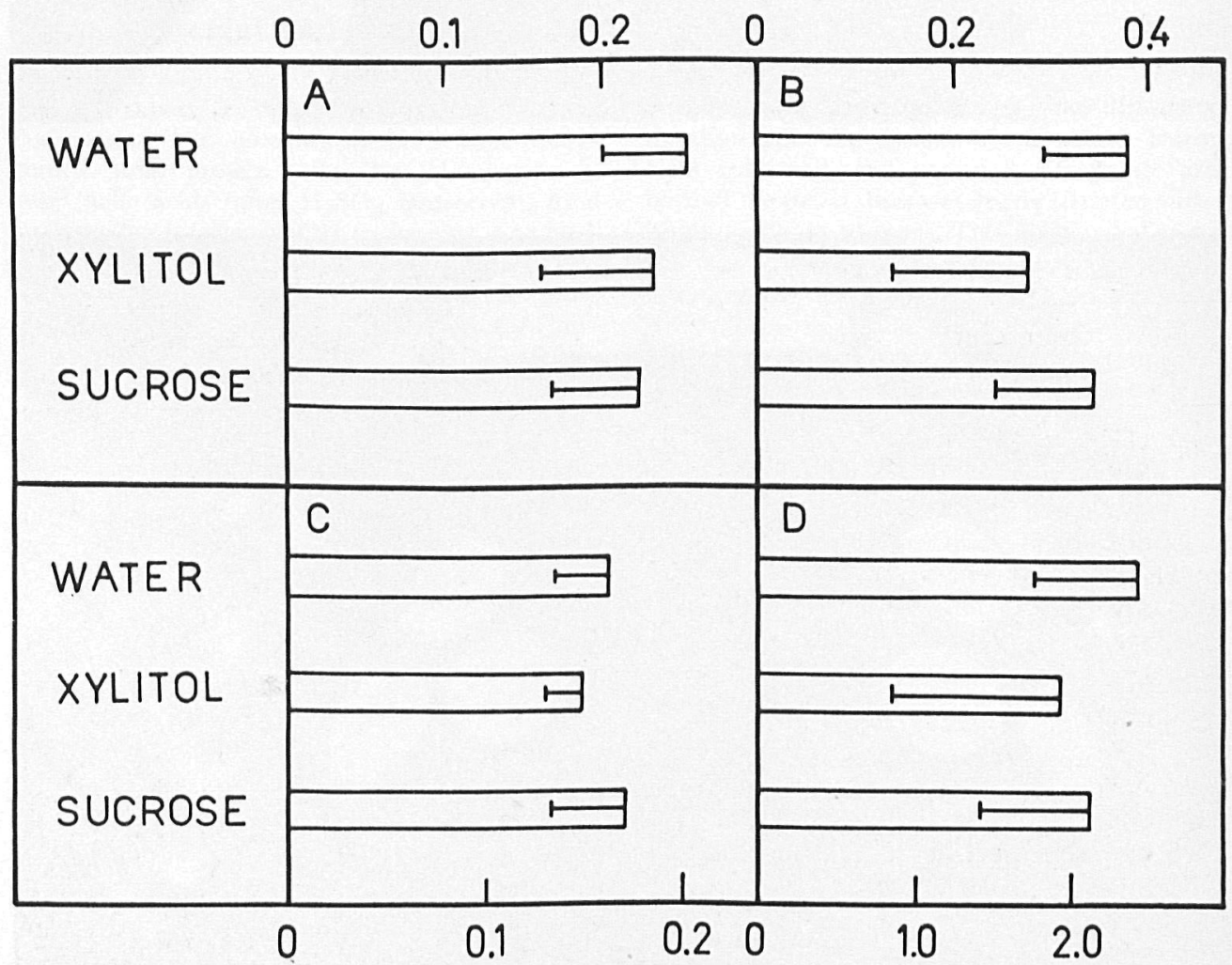

Fig. 2. Effect of type of chemical stimulation on concentration of total protein (A, in $\mathrm{mg} / \mathrm{ml}$ ), sialic acids (B, in $\mu \mathrm{mol} / \mathrm{mg}$ total protein), carbohydrates $(\mathrm{C}$, in $\mathrm{mg} / \mathrm{mg}$ total protein) and ratio of sialic acids to carbohydrates (D, in $\mu \mathrm{mol} / \mathrm{mg}$ ), of HPS. Values shown are means $\pm \mathrm{SD}$ expressed as the amount of substance per ml of alkaline extraction solution of paper discs (for total protein), or per $\mathrm{mg}$ total protein (for sialic acids and carbohydrates). The number of subjects (samples) included was 16. Statistical significance levels are shown in Table 1. 
or practically no visible HPS. As mentioned above, there is no reliable method for the measurement of the total secretion rate of HPS. However, our visual evaluation revealed no detectable differences between the different chemical treatments. Weight determinations were also considered, but even this method can be seriously criticised. Our weight determinations showed, however, that the 5-min collection time resulted in an absorption of $53.4 \pm 6.6 \mathrm{mg}$ samples into the discs (mean weight of samples). As indicated elsewhere in this paper, the most reliable way of expressing the levels of HPS constituents is to give them per $\mathrm{mg}$ protein.

Fig. 2 shows the concentrations of protein, sialic acids and carbohydrates of HPS collected after the chemical stimuli. Table 1 gives the significance levels between the means of
Fig. 2. The effects of the stimulants did not differ profoundly, but significant differences were still found between certain treatments when statistical comparisons were carried out (Table 1). The overall trend was that water stimulation was associated with increased concentrations of all HPS constituents studied, the only exception to this rule being the level of total sugars expressed per mg protein (Fig. 2). The HPS obtained after xylitol stimulation contained fewer sialic acids and carbohydrates than the HPS obtained after other stimulations. The ratio of total sialic acids to total sugars was also the smallest after xylitol treatment.

There were considerable individual differences between the specific enzyme activities measured. When the specific activities were compared, Leu-2-NA was hydrolyzed twice

Table 1

Significance levels between means in chemical analysis of HPS constituents

\begin{tabular}{|c|c|c|}
\hline $\begin{array}{l}\text { Constituent } \\
\text { treatments to be compared }\end{array}$ & $\begin{array}{l}\text { Wilcoxon matched-pairs } \\
\text { signed-ranks test** }\end{array}$ & $\begin{array}{l}t \text {-test for paired } \\
\text { comparisons } * *\end{array}$ \\
\hline \multicolumn{3}{|l|}{ Protein $(\mathrm{mg} / \mathrm{ml})^{*}$} \\
\hline $\mathrm{S} / \mathrm{W}$ & ++ & ++ \\
\hline $\mathrm{X} / \mathrm{W}$ & NS & NS \\
\hline $\mathrm{S} / \mathrm{X}$ & NS & NS \\
\hline \multicolumn{3}{|l|}{ Sialic acids $(\mu \mathrm{mol} / \mathrm{mg})$} \\
\hline $\mathrm{S} / \mathrm{W}$ & NS & NS \\
\hline $\mathrm{X} / \mathrm{W}$ & ++ & +++ \\
\hline $\mathrm{S} / \mathrm{X}$ & NS & + \\
\hline \multicolumn{3}{|l|}{ Carbohydrates $(\mathrm{mg} / \mathrm{mg}$ ) } \\
\hline $\mathrm{S} / \mathrm{W}$ & NS & NS \\
\hline $\mathrm{X} / \mathrm{W}$ & NS & NS \\
\hline $\mathrm{S} / \mathrm{X}$ & + & ++ \\
\hline \multicolumn{3}{|c|}{ Sialic acids/carbohydrates $(\mu \mathrm{mol} / \mathrm{mg})$} \\
\hline $\mathrm{S} / \mathrm{W}$ & NS & NS \\
\hline $\mathrm{X} / \mathrm{W}$ & + & + \\
\hline $\mathrm{S} / \mathrm{X}$ & NS & NS \\
\hline
\end{tabular}

* The proteins are expressed per volume of the alkaline extraction solution and the sialic acids and carbohydrates are given per mg protein. S, sucrose; W, water; X, xylitol.

** The number of subjects included in statistical calculations was 16 (these subjects produced measurable values in all chemical analyses indicated). NS, not significant $(P>0.05) ;+$, $0.01<P \leq 0.05 ;++, 0.001<P \leq 0.001 ;+++, P \leq 0.001$. 


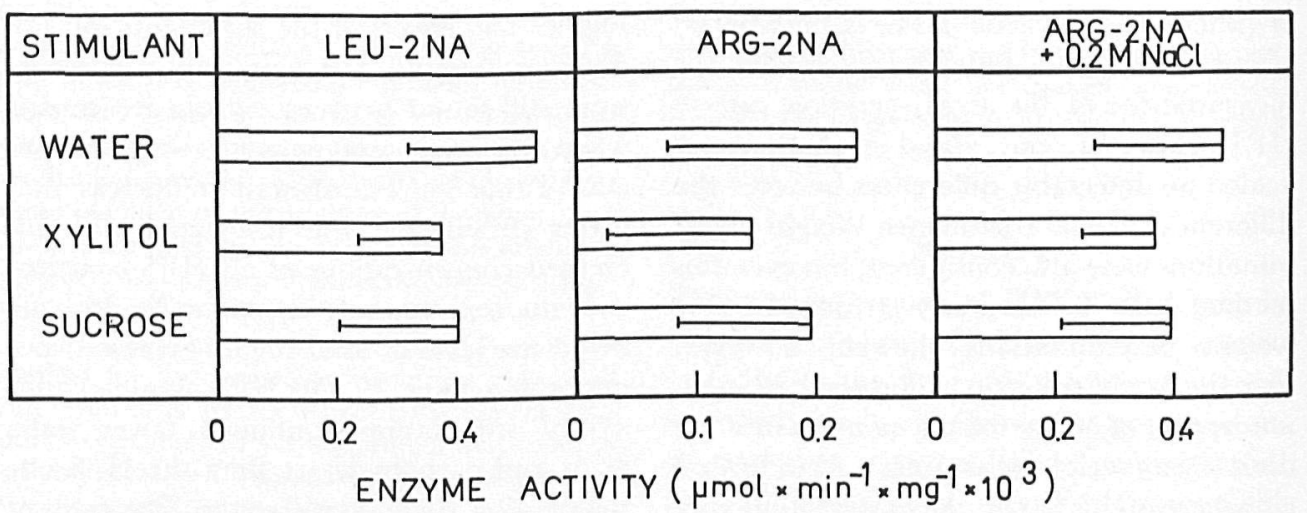

Fig. 3. Effect of type of chemical stimulation on activity of unspecific arylamidase-like enzymes of HPS. Values shown are the means $\pm \mathrm{SD}$, expressed as specific activities, i.e. $\mu \mathrm{mol} \times \mathrm{min}^{-1} \times \mathrm{mg}$ soluble protein $^{-1} \times 10^{3}$. The number of subjects (samples) included was 16. Statistical significance levels are shown in Table 2 .

as rapidly as Arg-2-NA. With the latter substrate, $0.2 \mathrm{M} \mathrm{NaCl}$ increased the specific activity by $100 \%$ (Fig. 3 ). The rate increment of $0.2 \mathrm{M} \mathrm{KGl}$ was similar to that of 0.2 $\mathrm{M} \mathrm{NaCl}$, suggesting that the salt effect was caused by $\mathrm{Cl}^{-}$. The results are not shown for Ala-2-NA in Fig. 3, since they were similar to those obtained with Leu-2-NA. All enzyme levels were smallest after xylitol stimulation, but the differences were significant only when comparing xylitol rinses with water rinses, when Leu-2-NA was used as substrate (Table 2).

\section{Discussion}

The number of minor salivary glands is estimated to be between 600 and 1000, and they occupy the submucosa throughout most of the oral cavity (12). The palatine salivary glands are situated in the mucosa of the hard and soft palate. These glands are mucous glands based on cell morphologic characteristics, without prejudice to the histochemical definition of the secretion product (13). Although the exact total volume of saliva produced by these glands daily is not known, the contribution of HPS may be considered essential to oral health. Only a few research groups have shown interest in the chemical composition of HPS (14-17). In studies where HPS is collected with filter paper, special attention should be paid to the fact that HPS proteins, enzymes and mucopolysaccharides may bind to Whatman filter papers rather strongly; only a smaller portion can be extracted with water only (1). Treatment of the filter paper discs with various salt solutions or Triton may in turn cause selective desorption, interfere with subsequent chromatography or affect enzyme stability. Although the desorption of HPS enzymes from the filter paper discs may not have been complete in the present study, the results are, however, comparable between the treatment groups. The enzymes were deliberately extracted with water only, in order to maintain their full activity, whereas the stronger treatment with alkali was considered to liberate virtually all carbohydrate and protein material for analyses.

A part of the variation seen in the data above results from the fact that the six paper discs from each subject were treated in $0.5 \mathrm{ml}$ water, in spite of the fact that different subjects produced HPS at different rates. 
Table 2

Statistical significance levels in determination of HPS arylamidase activity

\begin{tabular}{ccc}
\hline $\begin{array}{l}\text { Enzyme substrate } \\
\text { treatments to be compared }\end{array}$ & $\begin{array}{c}\text { Wilcoxon matched-pairs } \\
\text { signed-Ranks Test** }\end{array}$ & $\begin{array}{c}\text { t-test for paired } \\
\text { comparisons** }\end{array}$ \\
\hline Ala-2NA* & NS & + \\
S/W & NS & + \\
X/W & NS & NS \\
S/X & & + \\
Leu-2NA & NS & ++ \\
S/W & + & NS \\
X/W & NS & NS \\
S/X & & NS \\
Arg-2NA & NS & NS \\
S/W & + & \\
X/W & NS & NS \\
S/X & & NS \\
Arg-2NA $(+0.2 \mathrm{M} \mathrm{NaCl)}$ & NS & NS \\
S/W & NS \\
X/W & NS & \\
S/X & & \\
\hline
\end{tabular}

* The enzyme activity in $\mu \mathrm{mol} \times \mathrm{min}^{-1} \times \mathrm{mg}^{-1}$, was tested with the 2-naphthylamines of L-alanine, Lleucine and L-arginine. S, sucrose; W, water; $\mathrm{X}$, xylitol.

** The number of subjects included in statistical calculations was 16 (these subjects produced measurable enzyme activity in all determinations). NS, not significant $(P<0.05) ;+, 0.01<P \leq 0.05$; ,$++ 0.001<P \leq 0.01$.

The present procedure was, however, considered to allow more reliable comparison between the stimulants, since exact volume or flow rate determinations of total HPS are impossible due to varying viscosity of the multitude of drops appearing on the palate. Because weight losses were also possible during the handling of the discs, it was considered feasible to express most of the chemical data per mg protein.

Physiologically or pharmacologically active substances may be assumed to effect the secretion of HPS. The differences in the composition of HPS between the three chemical stimulants used, although statistically significant, were, however, considered to result from physiologic and normal responses of the secretory units to the stimulants. These differences were consistent in that sense that treatment with both carbohydrates was almost regularly associated with smaller concentrations of the compounds studied (expressed per mg protein) than treatment with water only. These may have been caused by more thorough depletion of the secretory units during the 2-min rinsing-chewing period that preceded sample collection, as a result of the use of sweet carbohydrate solutions. The collection and analyses of HPS in this study thus relate to material that was subsequently secreted; no information was obtained from the properties of HPS secreted during the chemical stimulation proper. It is assumable that water stimulation produced slightly less HPS (although this could not be accurately measured), with a resultant, smaller loss of enzymes, protein and other HPS constituents. In connection with water 
stimulation, the subsequent 5-min sample collection thus produced HPS that contained slightly higher amounts of the enzymes and substances studied. Our results indicated, however, that there could be small differences in the secretion rates between the various stimulants, although the subjective volume and flow rate evaluations suggested the opposite.

The rate increment caused by $0.2 \mathrm{M} \mathrm{NaCl}$ in the hydrolysis of Arg-2-NA is interesting, since it suggests that HPS contains $\mathrm{Cl}^{-}$activated aminopeptidase-like enzymes that have been found in numerous animal tissues, but not in saliva $(5,18)$. Our previous study on HPS revealed a less significant although clearly demonstrable $\mathrm{Cl}^{-}$-activation (1). Our more detailed $\mathrm{NaCl}$ studies that will be published later showed that the use of $0.2 \mathrm{M}$ $\mathrm{NaCl}$ anyway revealed a true $\mathrm{Cl}^{-}$effect. The difference between the degrees of $\mathrm{Cl}^{-}$activation observed in this and the previous study may result from differences in the collection of HPS. This presupposes that the HPS collected can be regarded as pure, glandular saliva and the filter paper discs did not contain any significant amounts of desquamated epithelial cells that would display arylamidase activity. Our conclusion is that the small number of epithelial cells that possibly could have attached to the paper discs, would not explain the remarkable degree of $\mathrm{Cl}^{-}$-activation observed. These studies thus indicate that HPS does contain $\mathrm{Cl}^{-}$-dependent arylamidases that have not been described previously in any type of pure, glandular saliva. It is possible that these enzymes resemble the true $\mathrm{Cl}^{-}$dependent arginine aminopeptidases (EC 3.4.11.6). Their significance to HPS remains to be elucidated. It is necessary to point out that the $\mathrm{Cl}^{-}$-effect was observed with Arg-2NA only. As previously emphasized, the $\mathrm{Cl}^{-}$dependent arylamidases may play a significant role in inflammatory processes $(5,18)$.

The large number of subjects from whom HPS could not be collected should, of course, lead to a reconsideration of the methods of stimulation and development of a more consistent approach. However, the purpose of this study was not to develop a method that would produce HPS from all subjects. Furthermore, if the procedure used, a combination of masticatory, gustatory and mechanical stimulation, does not produce detectable HPS from a subject, it is expected that such patients do not produce large amounts of HPS even under normal (or any) conditions. This could be regarded as an interesting physiologic feature that should be considered in subjects wearing total dentures, for example. Therefore, the apparent weakness of the present stimulation procedure may rather be regarded as a decisive advantage in the screening of poor secretors of HPS.

The design for stimulation of HPS, a combination of simultaneous masticatory and gustatory stimulation followed by mechanical manipulation, seems complicated. However, the accurate repetition of the procedure and the fact that the sweeteners (and water) were the only variables in the treatment, seem to allow the above conclusions to be drawn on the effects of various stimuli on HPS composition. Therefore, with the present design for stimulation, it is possible to attribute compositional variations to a particular factor, in this case the sweeteners (or water) used. This study leaves open, of course, a number of questions. For example, it would be of interest to know what happens when the palate is not gently stimulated, or when it is stimulated without a prior rinsing/chewing procedure. Emphasis should also be placed on our preliminary observation according to which more HPS is secreted from the left palate than from the right palate. These and other aspects of HPS secretion will be elucidated in our subsequent studies.

\section{References}

1. Mäkinen KK, Virtanen KK, Söderling E, Kotiranta J. Composition of human palatine 
gland secretions and evidence for the presence of specific arylamidases. Arch Oral Biol 1983; 28: $893-4$.

2. Mäkinen KK, Saheinin A. Turku sugar studies. VII. Principal biochemical findings on whole saliva and plaque. Acta Odontol Scand 1975; Suppl 70: 129-71.

3. MÄkinen KK, Saheinin A. Xylitol and dental caries. Ann Rev Nutr 1982; 2: 133-50.

4. MäKINEN KK. Biochemical principles of the use of xylitol in medicine and nutrition with special consideration of dental aspects. Experientia 1978; Suppl 30.

5. MÄKINEN KK. Occurrence and properties of arginine aminopeptidases. In: HANSON H, Bohley P, eds. Intracellular protein catabolism. Leipzig: Johan Ambrosius Barth, 1975; 45060.

6. MÄkinen KK, Mäkinen P-L. Purification and characterization of two human erythrocyte arylamidases preferentially hydrolysing $\mathcal{N}$-terminal arginine or lysine residues. Biochem f 1978; 175: 1051-67.

7. Mäkinen KK, Oкsala E. Evidence on the involvement in inflammation of an enzyme resembling aminopeptidase B. Clin Chim Acta 1973; 49: 301-9.

8. Mäkinen KK, Virtanen KK. Aminopeptidase B in human serum. Clin Chim Acta 1976; 67: 213-8.

9. Virtanen KK, Mäkinen KK, Oksala E. Activity of arginine aminopeptidases and phosphatases in inflamed palatal mucosa in denture stomatitis: a histochemical and biochemical study. 7 Dent Res 1977; 56: 674 84 .

10. Söderling E, Knuuttila M, Mäkinen KK. Aminopeptidase B-like enzymes in leukocytes. FEBS Lett. 1977; 76: 219-25.
11. Knuuttila M, Virtanen K, Söderling E, MÄKINEN KK. A chloride-activated aminopeptidase in rat inflammatory exudate: properties and evidence of the origin of the enzyme. Biochem Biophys Res Commun 1978; 81: 374-81.

12. Ten Gate AR. Oral histology, development, structure and function. Saint Louis: Mosby, 1980; 304-6.

13. Young JA, Van Lennep EW. The morphology of salivary glands. New York: Academic Press, 1978; 26-48, 118-23.

14. KaAber S. Sodium and potassium content in human palatine gland secretion. Arch Oral Biol 1977; 22: 529-32.

15. Hensten-Pettersen A. Minor salivary gland secretions. In: Kleinberg I, Ellison SA, Mandel ID, eds. Proceedings saliva and dental caries. Spec Suppl Microbiology Abstracts 1979; 81-7.

16. Shiba A, Sano K, Nakao M, Hayashi T. A new method of collecting saliva from human palatine glands for electrophoretic study. Arch Oral Biol 1980; 25: 503-4.

17. Shiba A, Sano K, Nakao M, Kobayashi K, IGARASHI Y. Analysis of human palatine salivary proteins by isoelectric focusing in agarose. Arch Oral Biol 1983; 28: 363-4.

18. MäkINEN KK. $\mathrm{Cl}^{-}$in the regulation of enzyme activity. In: Barth A, Haschen R, Laibagh FH, Possin H, Schowen RL, eds. Molecular and cellular regulation of enzyme activity. Halle: Martin-Luther-Universität Halle-Wittenberg, 1984; Part II, 11-58. 
This document is a scanned copy of a printed document. No warranty is given about the accuracy of the copy. Users should refer to the original published version of the material. 